NASA Technical Memorandum 103139

AIAA-90-2726

\title{
Advanced Tube-Bundle Rocket Thrust Chamber
}

John M. Kazaroff

National Aeronautics and Space Administration

Lewis Research Center

Cleveland, Ohio

and

Albert J. Pavli

Sverdrup Technology, Inc.

Lewis Research Center Group

Brook Park, Ohio

Prepared for the

26th Joint Propulsion Conference

cosponsored by the AIAA, SAE, ASME, and ASEE

Orlando, Florida, July 16-18, 1990 


\title{
ADVANCED TUBE-BUNDLE ROCKET THRUST CHAMBER
}

\author{
John M. Kazarof $f$ \\ National Aeronautics and Space Administration \\ Lewis Research Center \\ Cleveland, Ohio 44135
}

and

\author{
Albert J. Pavli \\ Sverdrup Technology, Inc. \\ Lewis Research Center Group \\ Brook Park, Ohio 44142
}

\begin{abstract}
SUMMARY
An advanced rocket thrust chamber for future space application is described along with an improved method of fabrication. Potential benefits of the concept are improved cyclic life, reusability, reliability, and performance. Performance improvements are anticipated because of the enhanced heat transfer into the coolant which will enable higher chamber pressure in expander cycle engines. Cyclic life, reusability and reliability improvements are anticipated because of the enhanced structural compliance inherent in the construction. The method of construction involves the forming of the combustion chamber with a tube-bundle of high conductivity copper or copper alloy tubes, and the bonding of these tubes by an electroforming operation. Further, the method of fabrication reduces chamber complexity by incorporating manifolds, jackets, and structural stiffeners while having the potential for thrust chamber cost and weight reduction.
\end{abstract}

\section{BACKGROUND}

Through the years many forms of rocket combustion chamber construction have been successfully employed. Among the most successful has been the brazed-tube construction used in regeneratively cooled flight engines such as the F-1 and J-2 (Saturn), the RL10 (Centaur) and the LR87-AJ and LR91-AJ series of engines ( $\mathrm{Titan}$ ). Figure 1 is a photograph of the RL10 engine. The RL10 is a liquid hydrogen-liquid oxygen engine using an expander-cycle to power its propellant pumps. The hydrogen, which is used as the turbine working fluid, is pressurized by the fuel pump, circulates through the cooling tubes picking up heat in the cooling process and is then expanded through the turbine to drive the propellant pumps. When the fuel exits the turbines it is then routed to the injector and burned in the combustor. By this means any residual energy left in the fuel is carried back into the combustion chamber, hence the name "regenerative" cooling. A section through a brazed-tube-bundle is shown in figure 2. The top view shows the jacket and jacket seam with the doubler strip. The lower view shows a section through the above segment with doubler overlapped on the jacket seam. Careful distribution of the braze material is evident in this view. The manufacturing processes used in producing these brazed-tube-bundle type combustion chambers has become very well developed over the years. Even so, the procedure of stacking the tubes is a very labor intensive, hand operation requiring selective fit in order to achieve the very close

Copyright (c) 1990 by the American Institute of Aeronautics and Astronautics, Inc. No copyright is asserted in the United States under Title 17, U.S. Code. The U.S. Government has a royalty-free license to exercise all rights under the copyright claimed herein for Governmental purposes.

All other rights are reserved by the copyright owner. 
dimensional tolerances needed to successfully furnace braze the tubes together. These dimensional tolerances are required since the primary control of braze material location relies on surface tension effects (capillary action) of the molten braze alloys. Also, this method of construction can sometimes involve the degradation of the metallurgical properties of the alloy-tubes because of exposure to the high brazing temperatures. The tendency of annealing, grain growth, specie migration into grain boundaries, and alloying with the braze material are always a concern when you must subject large assemblies to long duration heating in a furnace braze operation. In spite of these drawbacks, many successful combustion chamber configurations were produced by the above described construction method.

The need to increase performance and decrease size has led to configurations with higher chamber pressures and resultant increases in combustion chamber heat flux. Typical of this advanced class of engine is the space shuttle main engine (SSME). It is a staged-combustion cycle engine operating with liquid hydrogen and liquid oxygen propellants. The increased power required to pump the propellants to the higher chamber pressure is obtained by partially reacting some of the propellants in preburners to provide hot gas for the turbines. The turbine exhaust is then injected into the main combustor and burned with the remainder of the propellants. Because of higher chamber pressure, the heat flux is so severe that the combustion chamber cannot be made from the relatively low-conductivity type of alloys used in the brazed tube bundle configurations previously described and the only materials which would adequately transfer the heat are copper or silver and some of their higher conductivity alloys.

In the case of the SSME, the combustion chamber wall is made out of a single billet of copper alloy (NARloy-Z) into which are machined a series of axial grooves on the outside of the chamber wall. This type of construction is shown in figures 3 and 4 . These grooves serve as the coolant passages after layers of electroformed copper and nickel are deposited over the grooves on the outside diameter of the combustor. Although satisfactory for steady-state conditions, this type of configuration is very susceptible to thermal strains which exceed yield strength during startup and shutdown. This is largely caused by the very rigid nature of the construction. The relatively cold outside electroformed layer resists the thermal expansion of hot inner copper liner resulting in plastic deformation of the copper liner. The deformation accumulates cycle after cycle until the wall thickness in the center of the cooling passage is so thin that a pressure rupture occurs in the form of a crack. Figure 5 is a photograph of a section through such a failure.

The design of future engines will be done for a variety of missions and for a variety of requirements. In assessing the future requirements of space engines, one set of needs seems to dominate the picture. That is for an engine that will be space based, man-rated, and of high performance. In considering the man-rating requirements, a strong case can be made for an engine that operates on an expander-cycle instead of the more complicated staged combustion cycle. The advanced expander cycle engine is expected to operate in the realm of 1200 to 2000 psia chamber pressure as a result of improvements made to the combustion chamber cooling system and in its ability to provide energy to the turbopumps. This improved heat pickup is being pursued in several ways; (1) increased combustor length, (2) cooled combustor baffles, (3) coolant passage ribs and fins, (4) optimizing the combustor contraction-ratio, (5) high aspect 
ratio coolant channels, and (6) using tube construction for the combustor, (providing increased surface area).

Improved heat pickup via the use of the tube construction method for the combustor is expected to also provide considerable life improvement. This is because of increased circumferential structural compliance of the tube structure to the thermal expansions that would cause serious thermal stresses in a more rigid structure. More discussion on the merits and details of an advanced method of tube construction will follow.

\section{ADVANCED FABRICATION TECHNIQUES}

In the course of pursuing advanced fabrication techniques for producing rocket combustion chambers, several innovative and novel techniques have been developed at NASA Lewis Research Center. These techniques are employed to enhance the combined issues of performance, reliability, weight, and cost. Although all techniques described may be employed simultaneously they will be discussed individually.

(1) Electroformed bonding of tube-bundle combustion chambers. Instead of bonding tube-bundle assemblies with braze alloy in a furnace braze operation, where the tubes are subjected to an elevated temperature for a protracted duration, the tubes are bonded with an electroformed deposit of copper and/or nickel alloy done at essentially room temperature. This is especially important in the case of copper or copper alloy tubes since copper has a particular vulnerability to severe thermal degradation at furnace brazing temperatures. By electroform bonding at essentially room temperature several advantages can be realized. First, the deleterious effect of the elevated temperature on the physical properties of the tube alloy is avoided. Annealed structure and metallurgical grain growth along with alloying with the braze material are also avoided. Second, the bonding does not cause "fillets" on the hot gas side in the crevice between the tubes as braze material does, and so allows a higher degree of circumferential compliance to the structure. Third, dimensional tolerances are significantly relaxed since the very close tolerances to provide precise capillary flow of the braze material is not necessary with electroform bonding. With this comes a reduced number of fabrication operations, lower scrap rates in production, and also lower costs. Figure 6 is a photograph of a section of an electroform bonded tube chamber. Shown here is sectioned specimens of some early work in the bonding of stainless steel tubes with an electroformed nickel jacket. Figure 6(a) shows the closeout that was formed by two electroformed layers. After the first layer the high points were machined flat and the valleys were filled in with cerrobend alloy. The second layer then provided the cylindrical shell closeout structure.

Figure 6(b) shows the closeout that was formed by many electroformed layers. After three layers were deposited the high points were machined to the level of the valleys, without the need of any filler material. The remaining layers were then deposited onto the smooth cylindrical shape.

(2) Electroformed bonding of coolant manifolds and flanges. Instead of furnace brazing, torch brazing, or welding the manifolds and flanges to the combustion chamber as was done in the past, the manifolds and flanges are 
attached to the combustion chambers by electroform bonding/welding. The manifolds or flanges are either electroform "welded" by a deposit of copper and/or nickel alloy in place of the conventional weld fillet, or the entire manifold or flange is "grown" in place by a continuous electrodeposition. In either case a leak-tight and structurally sound attachment of manifolds or flanges can be achieved without the problems associated with the high temperature of brazing or welding (figs. 7 and 8 ).

(3) Electroforming of structural jacket for outside surface of combustion chamber. Instead of match machining an outer jacket to a very precise contour and then welding or brazing it to the combustion-chamber, the jacket can be formed in place by electroformed deposition of copper and/or nickel alloy directly to the outside of the combustion chamber. Because of this, considerable cost and time are saved due to not having to precision match-machine the jacket. Significant weight can be saved by not having to "double up" the material thickness at weld or braze locations to compensate for material degradation caused by the heat. Figure 2 shows a section through such a brazed construction.

(4) In-place electroforming of box-type thrust structure around the combustor throat. In the design of conventional thrusters, structural support is often provided in the form of a strut or shell structure around the throat region to carry some of the flexural and thrust loads. This has always involved welding or brazing of match machined fittings to the thrustor. This type of load-carrying structure can also be produced by electrodeposition. Once the outer jacket has been electroformed over the tube-bundle assembly with enough thickness to contain the combustion pressure forces, a spacer material is attached to span the throat area, as shown in figure 9. After proper activation of the spacer material and jacket contact surfaces a layer of copper and/or nickel alloy is electrodeposited over the area. When the proper thickness is achieved vent holes are drilled into the spacer material and it is removed by dissolving. What remains is a hollow box-type structure intimately attached to the chamber and nozzle. All of this fabrication is done without any heat from brazing or welding operations, no material degradation due to temperature, and no expensive precision match machining of parts.

(5) Inclusion of reinforcement wire into electrodeposited material. Further structural advantages can be realized by the inclusion of wire reinforcement to provide additional strength in the electrodeposited material. The reinforcement can be layered, or it can be applied continuously during the electrodeposition process. The reinforcement can be put anywhere in the electrodeposited material, and oriented in any direction. However, the description here will illustrate the application of simply providing additional hoop strength by orienting the wires in a circumferential direction in the cylindrical portion of the combustion chamber ( $\mathrm{fig} .9$ ). During the electroforming of the outer jacket the process is interrupted when the reinforcement is to be applied. At this time the reinforcement wire is wrapped around the chamber and mechanically held in place while the chamber is returned to the electroforming bath for the completion of the outer jacket. The outer jacket is then formed in place over the reinforcement wires which then become bonded and imbedded in place. Being intimately bonded to the electroformed substrate allows the reinforcement to load-share in the restraint of the circumferential forces as one would expect of the metal matrix composite material that has been so produced. Figure 10 is a photomicrograph of a wire reinforced, electrodeposited 
nickel specimen. Earlier work in this area (ref. 1) has shown that composite strengths can be predicted by the rule-of-mixtures approach quite accurately. Because of this, careful reinforcement design is possible and significant weight can be saved in both the jacket and outer throat support structure.

\section{DEMONSTRATION COMBUSTION CHAMBERS}

In an attempt to demonstrate several of the fabrication techniques simultaneously in the same test configuration a pair of demonstration combustion chambers were fabricated. They were of the standard plug and spool configuration used for fatigue testing at NASA Lewis; a cylindrical spool of 2.6 in. inside diameter 6 in. long. Figure 11 is a photograph of the two demonstration chambers after successfully passing a hydropressure test and a helium leak test. Although the chambers were not designed to be hot fired, they did demonstrate the technique of electroform bonding the copper tubes, building "grown on" manifold flanges, growing on a stiffening ring at the chamber midspan, and doing it all in a structurally sound and leak-tight manner. These demonstration chambers were hydrostatically pressure tested to 2400 psia, and then helium leak tested to 50 psia without any leaks. Figure 12 is a photograph of a piece of excess material trimmed from the flange end of a chamber prior to final closeout. Metallographic analysis of this specimen revealed intimate bonding of the tubes and good deposition of copper on the outside of the tube bundle.

\section{CONCLUSION}

Described is a method to produce a rocket combustion chamber with copper and/or copper alloy tubes. Until now this has not been considered as feasible because of copper's particular vulnerability to the severe thermal degradation expected as a result of the furnace braze operation needed to bond the tubes together. However in the procedure described herein, the tubes are bonded together by electrodeposition at essentially room temperature, and no thermal degradation occurs. This allows production of a combustion chamber that has the high thermal conductivity of a milled liner required for advanced expander cycle engines and more compliance than the brazed tubes to increase life. In addition the electroformed tube configuration will be less costly, more reliable, and increase heat transfer. Higher chamber pressures can be obtained due to the improved enthalpy extraction to the coolant provided by the increased wetted surface area (tubes instead of smooth liner). The cost is reduced by the relaxing of dimensional tolerances of the tubes and the absence of match machining requirements on the jacket, along with fewer fabrication operation steps. Weight is reduced by not needing thicker cross sections to compensate for heat affected zones caused by welding and brazing, and by thinner cross sections by virtue of wire reinforcing. Life is enhanced by both the strain reductions achieved by the compliant nature of the construction, and also the absence of material degradation caused by the heat of the weld and braze cycles. 


\section{REFERENCE}

1. McCandless, L.C., and Davies, L.G., "Development of Improved Electroforming Techniques - For Fabricating Regeneratively Cooled Thrust Chambers," General Technologies Corp., 6621 Electronic Drive, Springfield, VA 22151, Contract No. NAS3-15828, NASA CR-134480, 1973.

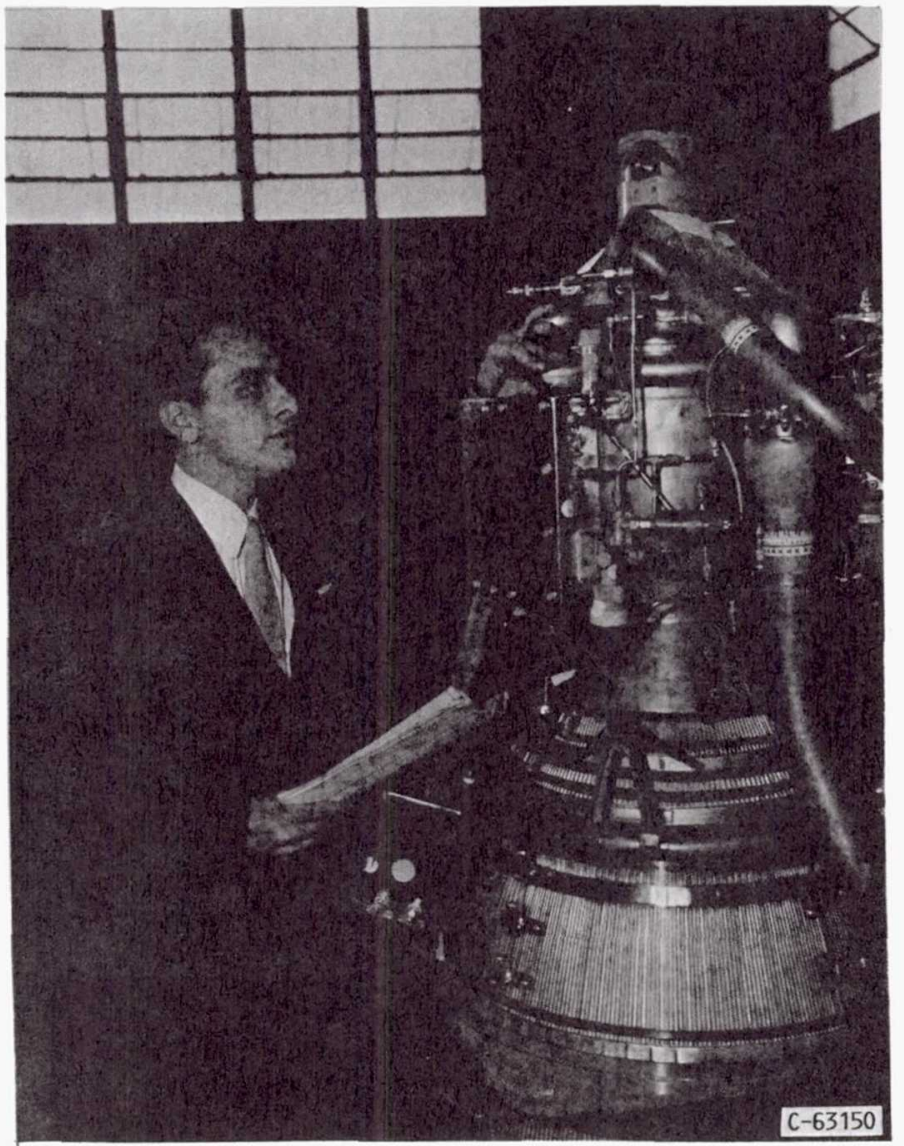

FIGURE 1. - PHOTO OF RL-10 ENGINE. 


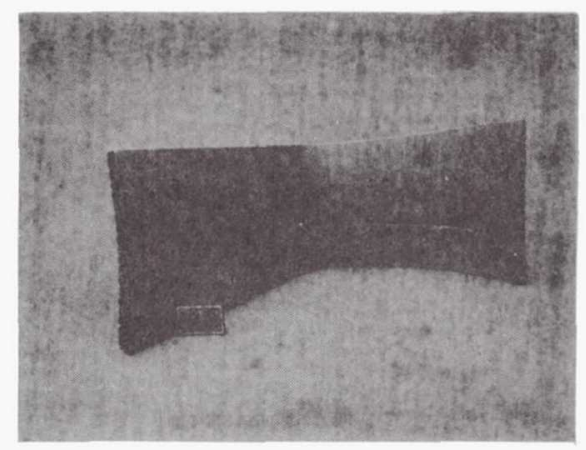

(a) THROAT SEGMENT WITH JACKET AND SEAM DOUBLER.

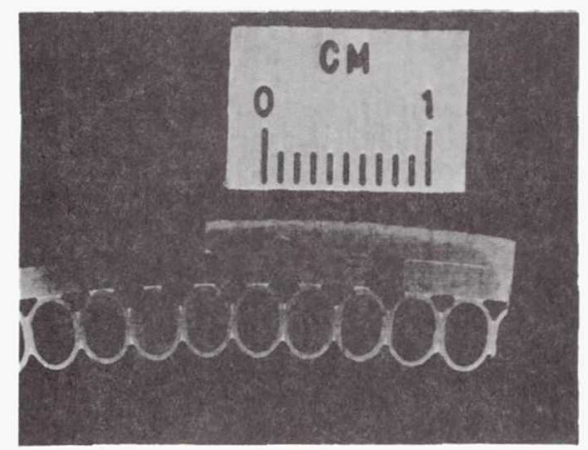

(b) SECTION OF ABOVE SEGMENT.

FIGURE 2. - PHOTO OF BRAZED TUBE CONSTRUCTION.

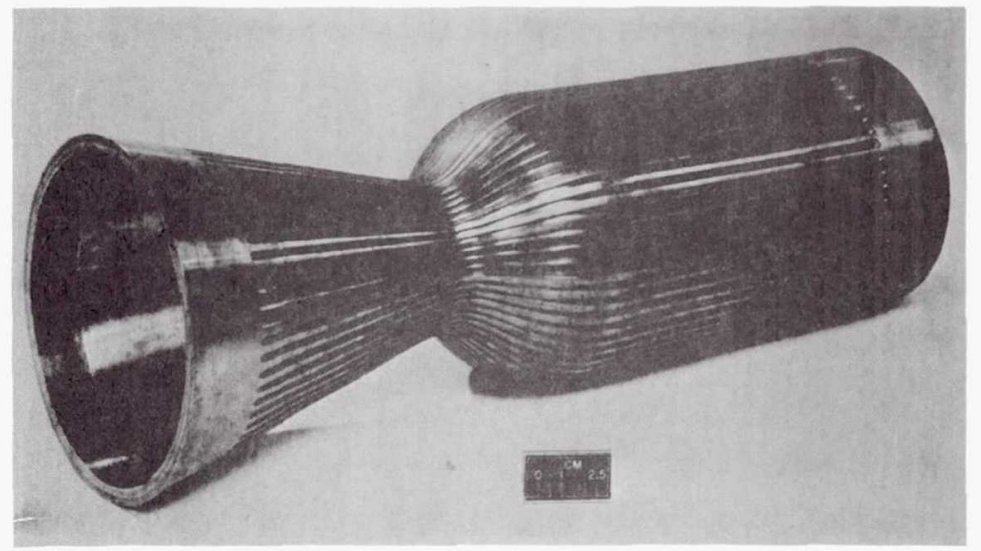

Figure 3. - Milled COPPER LiNER COMBUStion CHAMBER. 


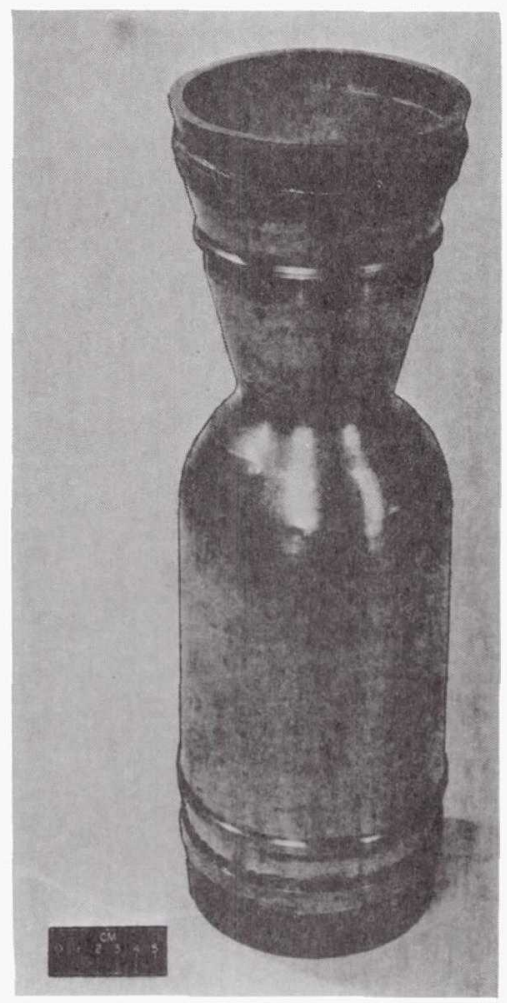

FIGURE 4. - MILLED COPPER LINER COMBUSTION CHAMBER WITH ELECTROFORMED NICKEL CLOSEOUT.

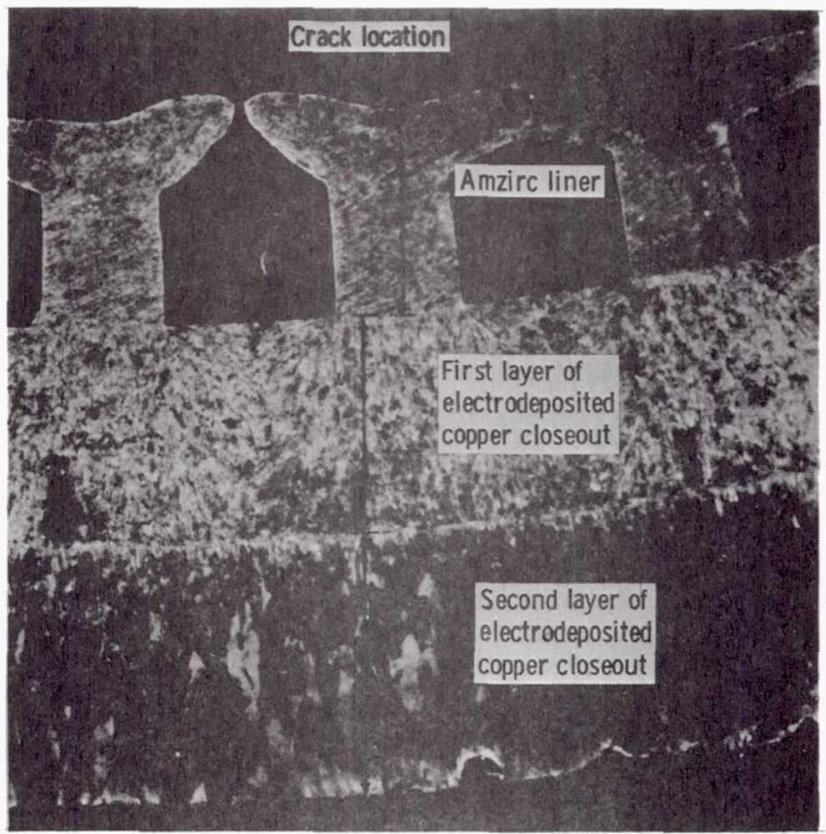

FIGURE 5. - CROSS SECTION THROUGH TYPICAL MILLED LINER FATIGUE FAILURE. 


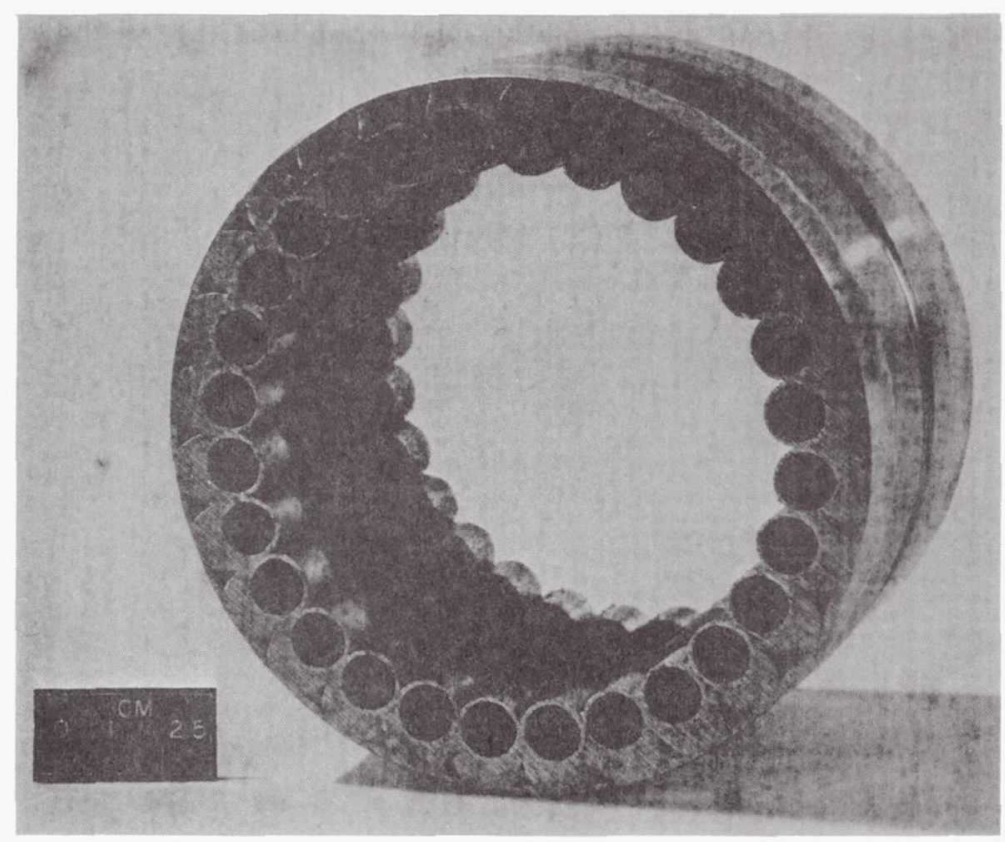

(a) ELECTROFORM BONDED TUBES.

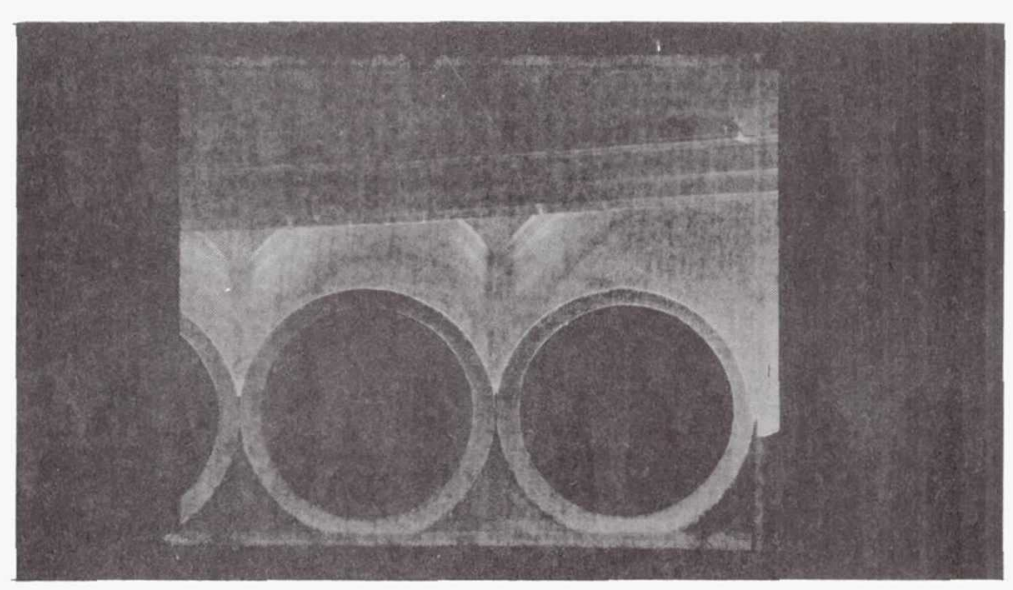

(b) ENLARGED VIEW.

FIGURE 6. - ELECTROFORM BONDING OF TUBES. 


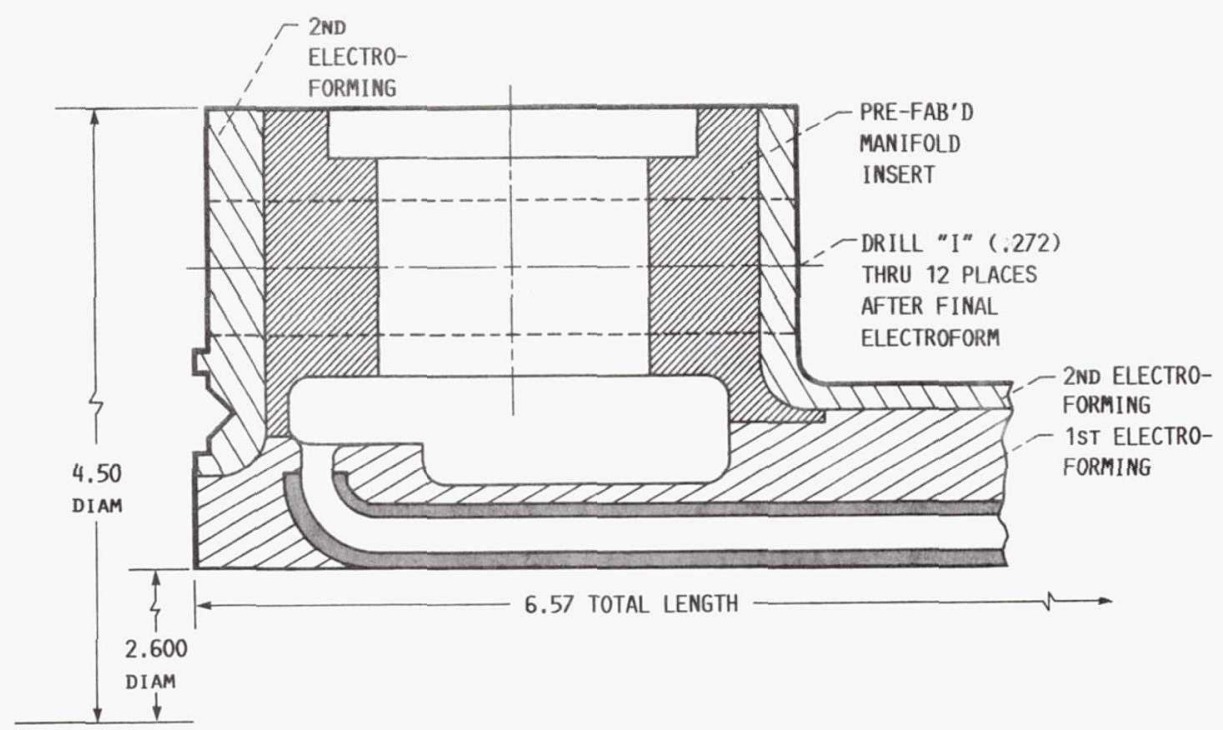

(a) EXAMPLE 1.

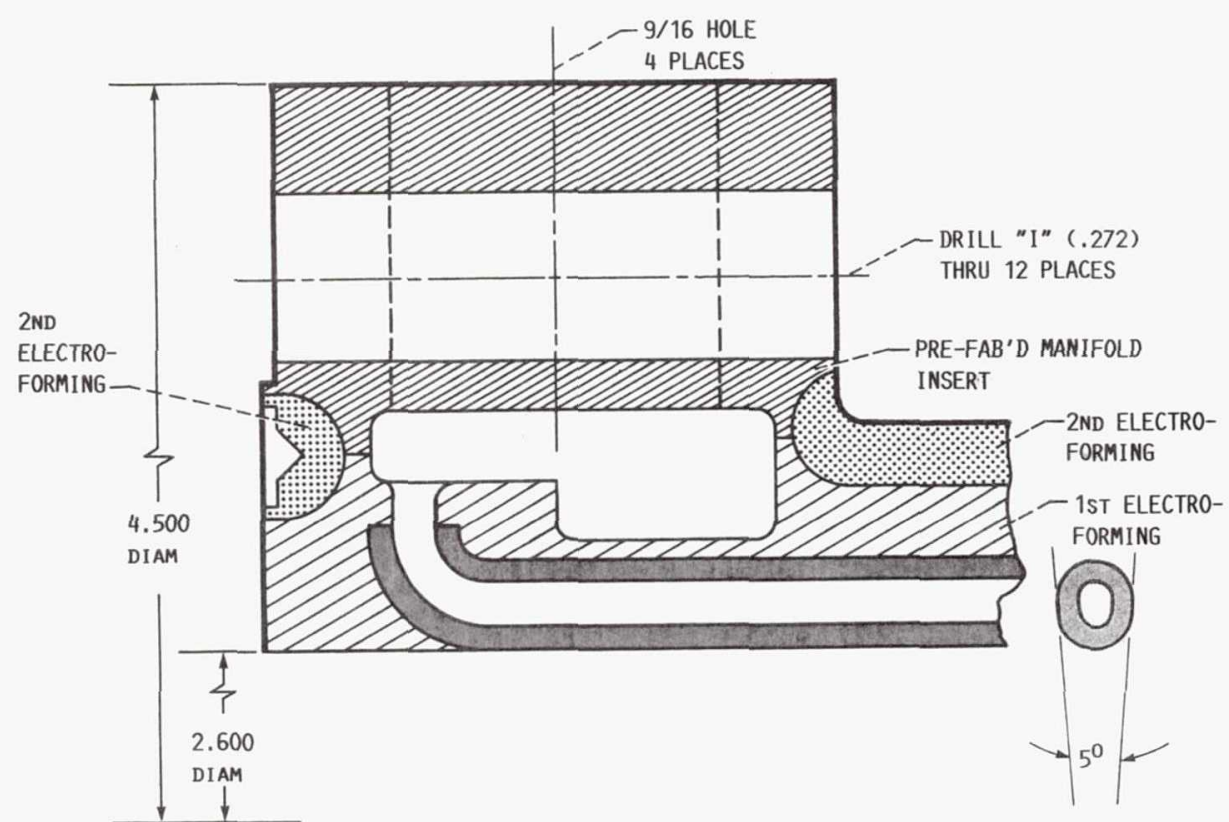

(b) EXAMPLE 2.

FIGURE 7. - ELECTROFORM WELDED MANIFOLD. 


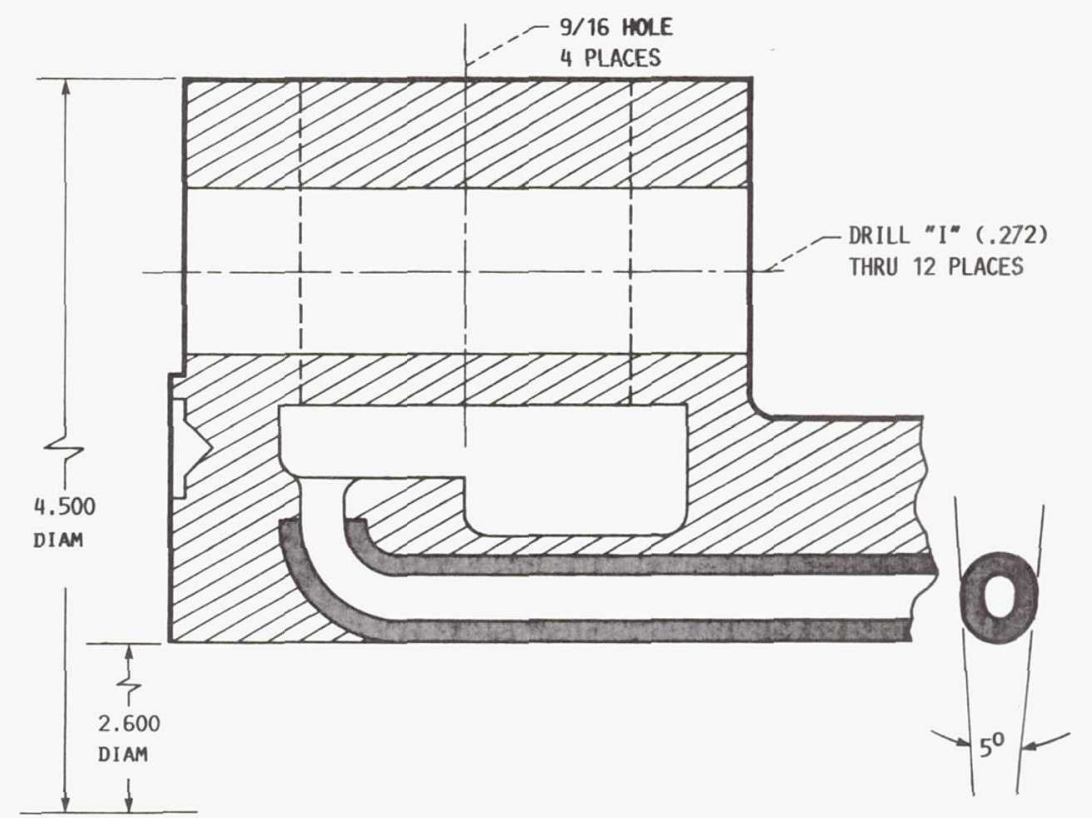

FIGURE 8. - EXAMPLE OF "GROWN-IN-PLACE" MANIFOLD-FLAMGE.

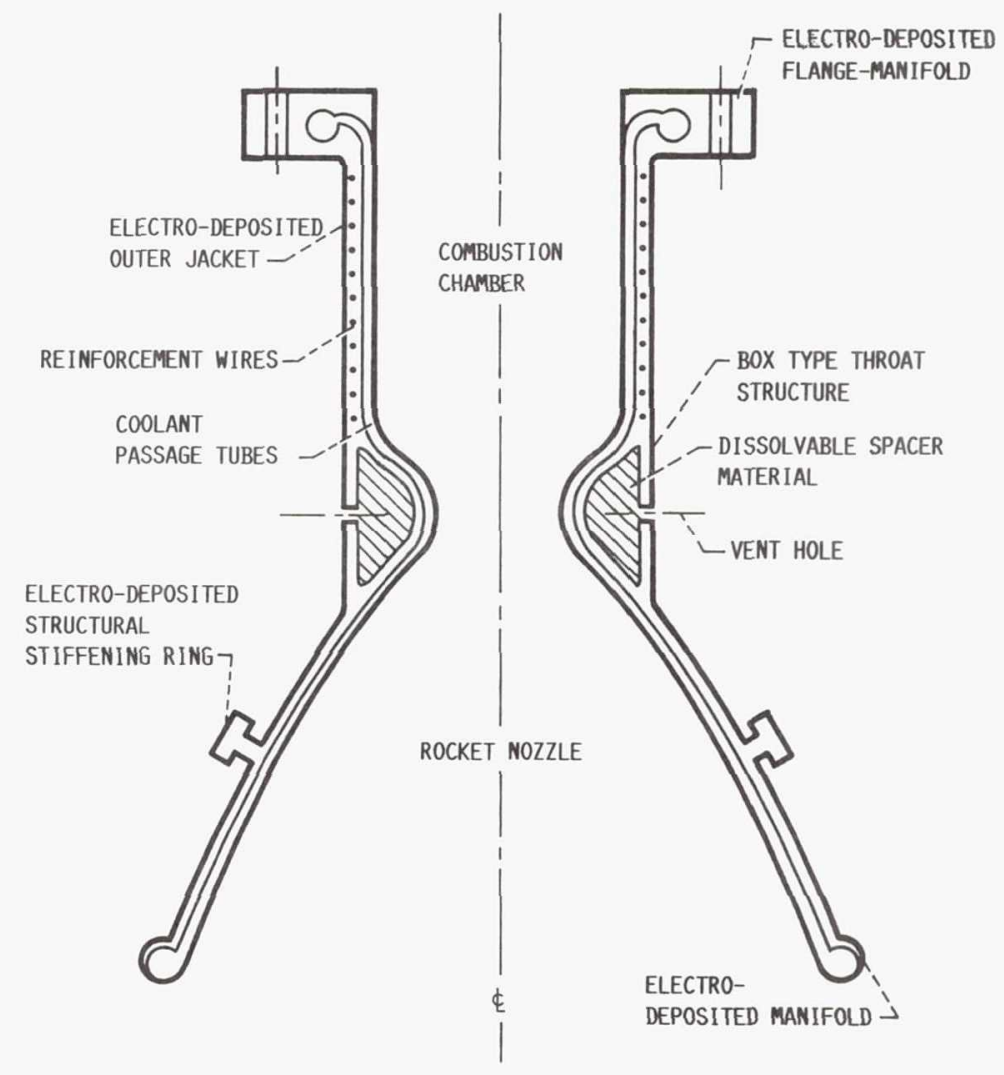

FIGURE 9. - DETAILS OF CONSTRUCTION. 


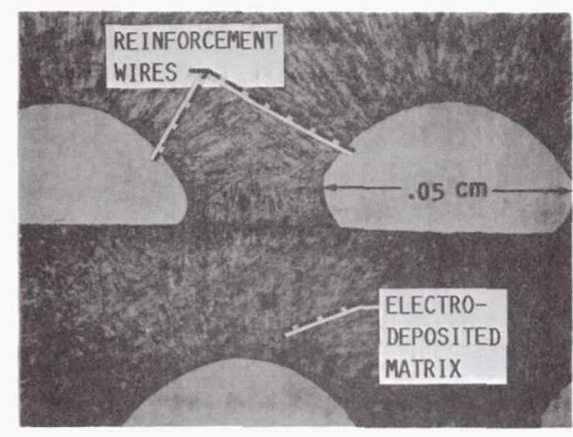

FIGURE 10. - PHOTOMICROGRAPH OF WIRE REINFORCED ELECTROFORMED NICKEL.

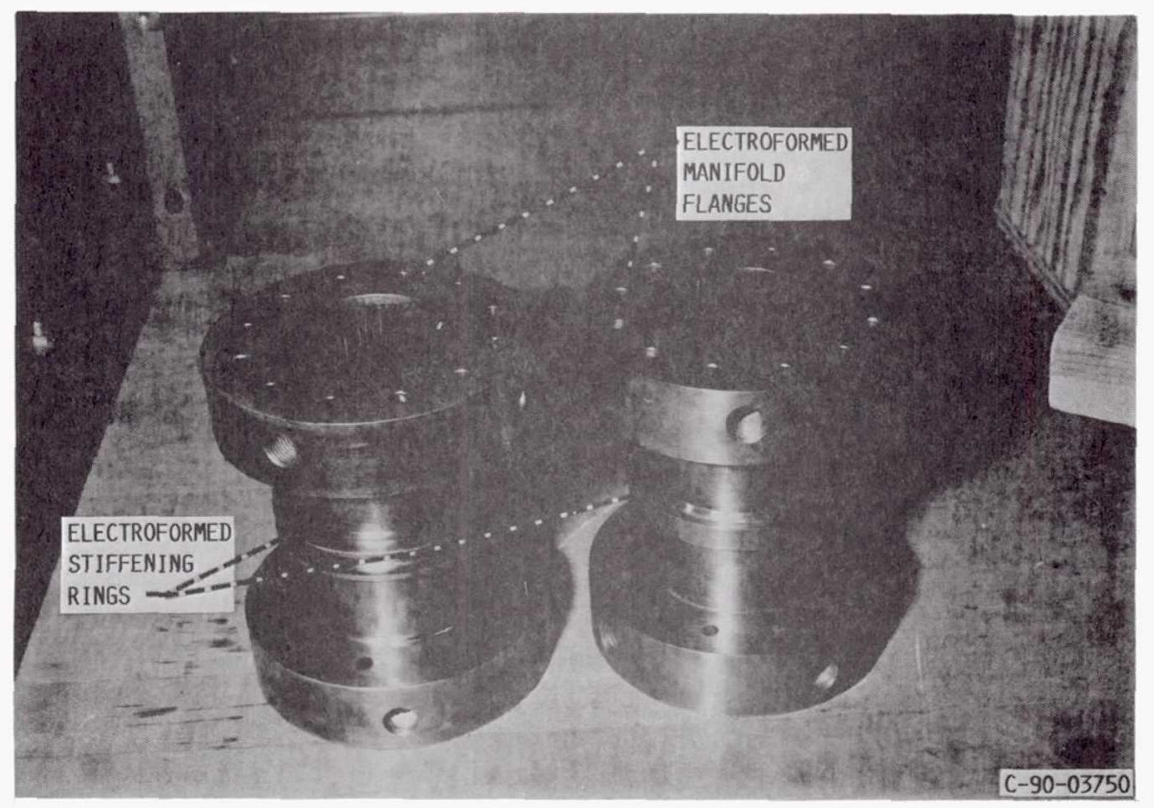

FIGURE 11. - PHOTOGRAPH OF DEMONSTRATION COMBUSTION CHAMBERS.

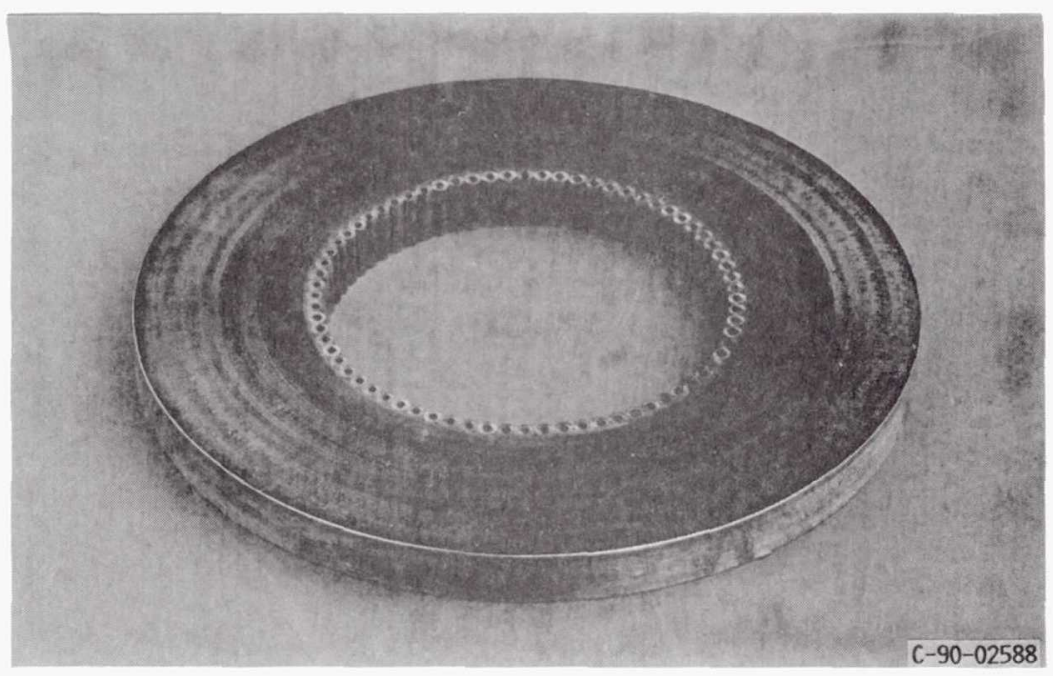

FIGURE 12. - PHOTOGRAPH OF SPECIMEN SHOWING TUBE BONDS. 


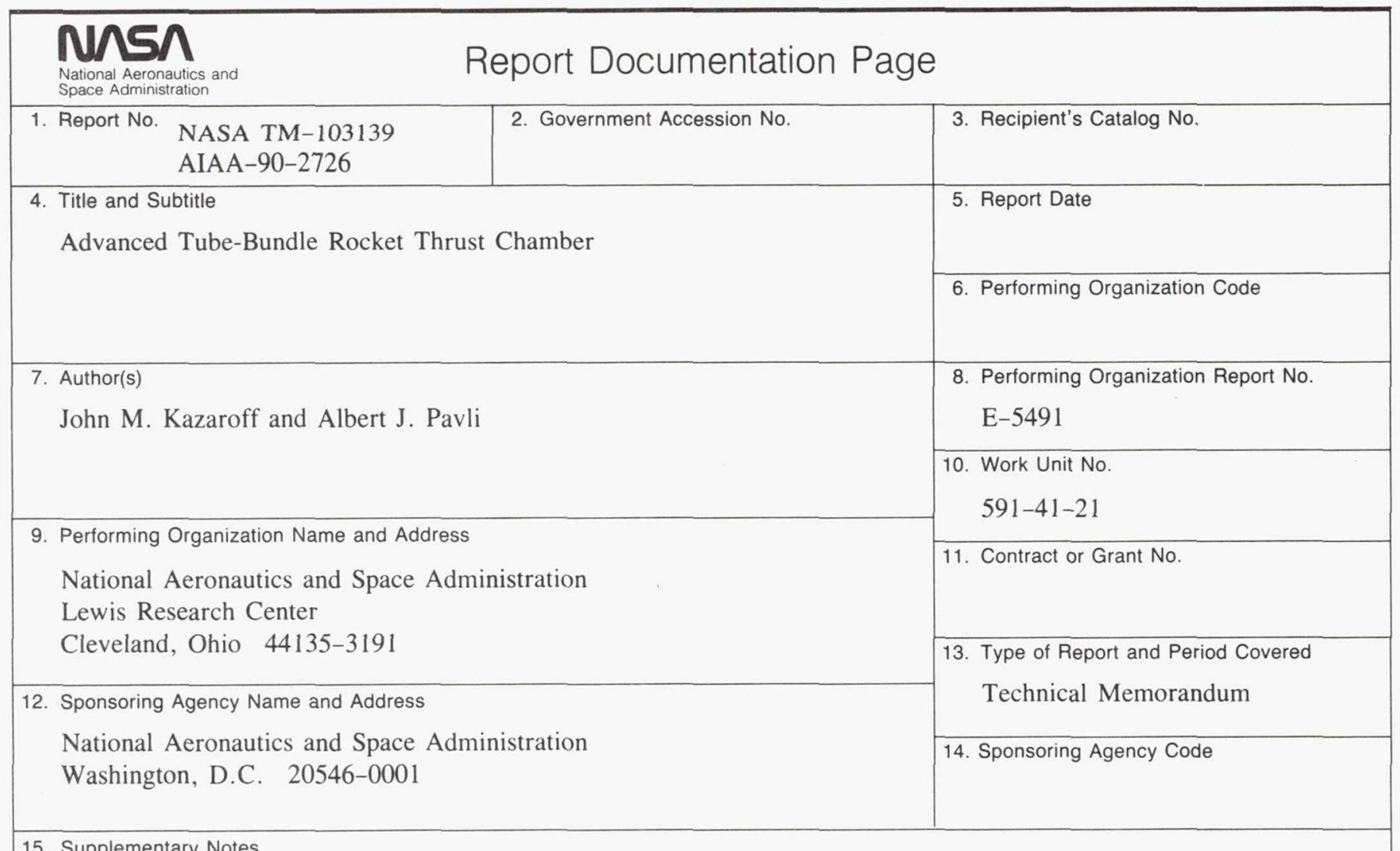

15. Supplementary Notes

Prepared for the 26th Joint Propulsion Conference cosponsored by the AIAA, SAE, ASME, and ASEE, Orlando, Florida, July 16-18, 1990. John M. Kazaroff, NASA Lewis Research Center. Albert J. Pavli, Sverdrup Technology, Inc., Lewis Research Center Group, 2001 Aerospace Parkway, Brook Park, Ohio 44142.

16. Abstract

An advanced rocket thrust chamber for future space application is described along with an improved method of fabrication. Potential benefits of the concept are improved cyclic life, reusability, reliability, and performance. Performance improvements are anticipated because of the enhanced heat transfer into the coolant which will enable higher chamber pressure in expander cycle engines. Cyclic life, reusability and reliability improvements are anticipated because of the enhanced structural compliance inherent in the construction. The method of construction involves the forming of the combustion chamber with a tube-bundle of high conductivity copper or copper alloy tubes, and the bonding of these tubes by an electroforming operation. Further, the method of fabrication reduces chamber complexity by incorporating manifolds, jackets, and structural stiffeners while having the potential for thrust chamber cost and weight reduction.

17. Key Words (Suggested by Author(s))

Copper, Tube, Electroforming, Cooled, Rocket chamber

18. Distribution Statement

Unclassified-Unlimited

Subject Category 20

19. Security Classif. (of this report) Unclassified

20. Security Classif. (of this page)

Unclassified
21. No. of pages

14
22. Price*

$\mathrm{A} 03$ 
National Aeronautics and Space Administration

Lewis Research Center

Cleveland, Ohio 44135

\section{Oriictal Business}

Penalty for Private Use $\$ 300$
FOURTH CLASS MAIL

ADDRESS CORRECTION REQUESTED

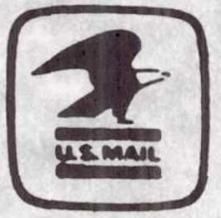

Postage and Fees Paid National Aeronautics and Space Administration NASA-451

\section{N/SA}

